\title{
Resumption of Positive-Pressure Ventilation Devices for Obstructive Sleep Apnea following Transsphenoidal Surgery: An Institutional Experience of a Surgical Cohort
}

\author{
Nicholas Gravbrot ${ }^{1}$ Heidi Jahnke ${ }^{1}$ William L. White ${ }^{1} \quad$ Andrew S. Little ${ }^{1}$ \\ ${ }^{1}$ Department of Neurosurgery, Barrow Neurological Institute, St. Joseph's \\ Hospital and Medical Center, Phoenix, Arizona, United States \\ Address for correspondence Andrew S. Little, MD, Department of \\ Neurosurgery, Barrow Neurological Institute, St. Joseph's Hospital \\ and Medical Center, 350 W. Thomas Rd., Phoenix, AZ 85013 , \\ J Neurol Surg B 2020;81:237-243. \\ United States (e-mail: Neuropub@barrowneuro.org).
}

\begin{abstract}
Keywords

- CPAP

- obstructive sleep apnea

- positive-pressure ventilation

- transsphenoidal surgery

Objectives Transsphenoidal surgery creates a skull base defect that may cause postoperative cerebrospinal fluid (CSF) leakage or pneumocephalus. This study reviewed the institutional experience of a pituitary center in managing patients who use positive-pressure ventilation (PPV) devices for obstructive sleep apnea (OSA) after transsphenoidal surgery, which risks disturbing the skull base repair.

Design Retrospective review.

Setting Pituitary referral center in a major metropolitan medical center.

Methods PPV was resumed at the discretion of the treatment team based on intraoperative findings and OSA severity. Perioperative complications related to resuming and withholding PPV were recorded.

Participants Transsphenoidal surgery patients with OSA using PPV devices.

Main Outcome Measures Intracranial complications before and after resuming PPV. Results A total of 42 patients met the study criteria. Intraoperative CSF leakage was encountered and repaired in $20(48 \%)$ patients. Overall, 38 patients resumed PPV (median: 3.5 weeks postsurgery; range: $0.14-52$ weeks) and 4 patients did not resume PPV. Postoperatively, no patient experienced CSF leakage or pneumocephalus before or after resuming PPV. Four (10\%) patients required temporary nocturnal supplemental oxygen at home, one patient was reintubated after a myocardial infarction, and one patient had a prolonged hospital stay due to chronic obstructive pulmonary disease exacerbation.

Conclusions Resuming PPV use after transsphenoidal surgery did not result in intracranial complications. However, delay in resuming PPV resulted in four patients requiring oxygen at home. We propose a preliminary PPV device management algorithm based on the size of the intraoperative CSF leak to facilitate future studies.
\end{abstract}

\section{Introduction}

The endonasal transsphenoidal approach is often the preferred method for treating symptomatic sellar lesions and other skull base pathologies. An inevitable consequence of this approach is the creation of an opening in the anterior skull base, which is used to access the tumor. This bony

received

January 22, 2018

accepted after revision

March 26, 2019

published online

May 17, 2019

opening places patients at a risk of developing a fistula between the nasal cavity and the intracranial space, which can result in a cerebrospinal fluid (CSF) leak, meningitis, or pneumocephalus. ${ }^{1-3}$ Tension pneumocephalus is an uncommon and emergent intracranial complication after transsphenoidal surgery, whereby intracranial air causes mass effect on the brain. ${ }^{4-7}$

(c) 2020 Georg Thieme Verlag KG Stuttgart · New York
DOI https://doi.org/ 10.1055/s-0039-1688795. ISSN 2193-6331. 
Obstructive sleep apnea (OSA) is common in the United States adult population, with an estimated prevalence of 3 to 7\%. ${ }^{8}$ As a result of obstruction of the upper airway, patients with OSA have repeated pauses in breathing while sleeping. OSA is the leading cause of daytime sleepiness and is associated with cardiac events, hypertension, depression, and diabetes mellitus. ${ }^{8}$ It is also common in patients with pituitary disorders such as acromegaly, Cushing's disease, and prolactinoma. ${ }^{9-14}$ Diagnosis of OSA typically entails an overnight sleep study, which compiles the results of several physiologic recordings during the study, including electroencephalogram (EEG), electromyogram, oronasal airflow, and oxygen saturation. ${ }^{8}$ The gold standard to characterize the severity of sleep apnea is the apnea-hypopnea index (AHI), which is the measure of apneas and hypopneas per hour of sleep. According to this measure, moderate OSA is defined as AHI $\geq 15$ and $<30$, whereas severe OSA is defined as AHI $\geq 30 .{ }^{15}$ Moderate-to-severe OSA is often treated with positive-pressure ventilation (PPV) devices such as continuous positive airway pressure (CPAP) devices or bilevel positive airway pressure (BiPAP) devices. ${ }^{16-18}$

Several recent case reports have drawn an association between OSA, PPV device use, and intracranial complications. ${ }^{6,19-23}$ The concern with using PPV devices after transsphenoidal surgery is that the pressure in the nasal airway applied by the PPV device disrupts the integrity of the reconstruction of the skull base. Early reinitiation of this therapy has been thought to be contraindicated after transsphenoidal surgery to allow the skull base to heal. However, withholding PPV after surgery may potentially cause harm by prolonging patient recovery and increasing the length of hospital stay, increasing patient fatigue, reintubation events, and cardiopulmonary events, and raising intracranial pressure due to retained $\mathrm{CO}_{2}$, which can result in a CSF leak. ${ }^{24,25}$ Furthermore, airway concerns secondary to OSA due to increased nasal edema or nasal packing or stents can be exacerbated after transsphenoidal surgery. Because outcome data are limited regarding PPV device use in these patients, guidelines for restarting PPV after transsphenoidal surgery are not available. In this retrospective review, we examined our institutional experience in managing patients with OSA who use PPV devices and have undergone transsphenoidal surgery. We focus on both the risks of restarting PPV devices and the potential harm to patients during the postoperative period before resuming PPV. We also propose a management algorithm that incorporates the size of the skull base defect.

\section{Methods}

\section{Study Design and Patient Population}

This study was a retrospective analysis of consecutive adult patients ( $>18$ years of age) with OSA who used a PPV device and who had undergone transsphenoidal surgery for pituitary and related skull base conditions at a single pituitary referral center within a major medical institution. Data abstracted from inpatient and outpatient medical records included patient demographics, tumor characteristics, surgical techniques, and OSA complications. Eligible patients were treated between May 1, 2013, and September 30, 2016, by two neurosurgeons (W. L. W. and A. S. L.).

The study was approved by the institutional review board at the participating institution. Due to the retrospective nature of the report, informed consent was not required. The study adhered to the principles set forth in the US Code of Federal Regulations, Title 45, Part 46, "Protection of Human Subjects" (revised January 15, 2009). The STROBE guidelines for cohort studies were used as the reporting guidelines for this study (https://www.strobe-statement.org/).

\section{Surgical Technique}

Standard transsphenoidal surgical techniques were used that employed either a uninostril microscopic approach or a binostril endoscopic approach., ${ }^{3,26}$ Methods of sellar repair were determined by the treating neurosurgeon. For small, weeping, low-flow CSF leaks, the sella was reconstructed with either a collagen sponge or a fat graft and a rigid sellar buttress. For high-flow leaks in patients undergoing endoscopic visualization, a multilayer closure was used that consisted of an inlay dural graft and a vascularized nasal septal flap. For high-flow leaks in patients undergoing microscopic visualization, a multilayer closure used abdominal fat and a rigid skull base buttress. CSF leaks were graded according to the classification by Esposito et al. ${ }^{1}$

\section{Obstructive Sleep Apnea Management}

The resumption of PPV was determined on a case-by-case basis at the discretion of the treating neurosurgeon in consultation with the neurocritical care service, given the lack of accepted clinical practice guidelines. The decision was based on the neurosurgeon's impression of intraoperative findings, the presumed risks of resuming use of the PPV device, and the severity of the patient's OSA stratified by AHI (when available). Continuous pulse oximetry monitoring was conducted in all patients during the first postoperative night and longer, as needed. Supplemental oxygen was provided using a humidified face tent, as needed. All patients were evaluated by either a pulmonologist or a hospitalist before discharge.

\section{Statistical Analysis}

Data were analyzed using descriptive statistics such as means, frequencies, and standard deviations.

\section{Results}

\section{Study Population}

During the study period (May 1, 2013, through September 30 , 2016), 499 patients underwent a total of 544 endonasal transsphenoidal operations for sellar or other anterior skull base pathologies. Of these 499 patients, 42 with OSA used a PPV device (38 CPAP and 4 BiPAP) preoperatively and were included in the analysis. Of these 42 patients, 30 (71\%) were men. The mean age was $58.5 \pm 10.6$ years, and the mean body mass index, calculated as weight in kilograms divided by height in meters squared, was $35.8 \pm 9.0$. The most common indication for surgery was nonfunctioning adenoma 
(18 patients; $43 \%$ ) followed by acromegaly ( 6 patients; $14 \%$ ) and Cushing disease ( 5 patients; $12 \%$ ). The characteristics of the 42 patients are summarized in - Table 1. All patients had at least 6 months of clinical follow-up.

\section{Surgical Procedure Details}

The 42 patients underwent a total of 46 endonasal transsphenoidal operations. One patient required three reoperations for staged debulking of a multiply recurrent prolactinoma. One

Table 1 Characteristics of 42 transsphenoidal surgery patients with obstructive sleep apnea

\begin{tabular}{|c|c|}
\hline Characteristic & $N(\%)^{\mathrm{a}}$ \\
\hline Male sex & $30(71)$ \\
\hline Age, mean \pm SD (year) & $58.5 \pm 0.6$ \\
\hline Body mass index, mean \pm SD & $35.8 \pm 9.03$ \\
\hline \multicolumn{2}{|l|}{$\begin{array}{l}\text { Preoperative positive-pressure } \\
\text { ventilation type }\end{array}$} \\
\hline Continuous positive airway pressure & $38(90)$ \\
\hline Bilevel positive airway pressure devices & $4(10)$ \\
\hline Tumor coronal height, mean \pm SD $(\mathrm{cm})$ & $1.9 \pm 0.74$ \\
\hline \multicolumn{2}{|l|}{ Diagnosis } \\
\hline Nonfunctioning adenoma & $18(43)$ \\
\hline Acromegaly & $6(14)$ \\
\hline Cushing's disease & $5(12)$ \\
\hline Pituitary apoplexy & $4(10)$ \\
\hline Rathke cleft cyst & $3(7)$ \\
\hline Prolactinoma & $2(5)$ \\
\hline Other $^{\mathrm{b}}$ & $4(10)$ \\
\hline \multicolumn{2}{|l|}{ Surgical approach in 46 operations } \\
\hline $\begin{array}{l}\text { Single-compartment } \\
\text { (transsphenoidal) approach }\end{array}$ & $41(89)$ \\
\hline Multicompartment approach & $5(11)$ \\
\hline Transsphenoidal, transclival & $1(2)$ \\
\hline $\begin{array}{l}\text { Transsphenoidal, transethmoidal, } \\
\text { transtubercular }\end{array}$ & $1(2)$ \\
\hline $\begin{array}{l}\text { Transsphenoidal, transclival, } \\
\text { transcavernous }\end{array}$ & $1(2)$ \\
\hline $\begin{array}{l}\text { Transsphenoidal, transclival, } \\
\text { transethmoidal, transsellar }\end{array}$ & $1(2)$ \\
\hline $\begin{array}{l}\text { Transsphenoidal, transclival, } \\
\text { transethmoidal, transmaxillary }\end{array}$ & $1(2)$ \\
\hline \multicolumn{2}{|l|}{ Intraoperative cerebrospinal fluid leak ${ }^{c}$} \\
\hline Grade 0 & $22(52)$ \\
\hline Grade 1 & $16(38)$ \\
\hline Grade 2 & $2(5)$ \\
\hline Grade 3 & $2(5)$ \\
\hline
\end{tabular}

Abbreviation: SD, standard deviation.

${ }^{a}$ Values are presented as number (percentage) or as mean \pm SD.

bother pathologies include one each: tuberculum meningioma, spindle cell oncocytoma, chordoma, and pituitary cyst.

${ }^{c}$ Cerebrospinal fluid leak as defined in Esposito et al. ${ }^{1}$ patient required same-day reoperation for evacuation of a sellar hematoma that resulted in optic chiasm compression. The standard transsphenoidal corridor alone was used in 41 (89\%) of the 46 operations, whereas 5 (11\%) operations required an expanded corridor, such as the transtubercular or transclival approach. CSF leakage was observed intraoperatively in $20(48 \%)$ of the 42 patients. The skull base was repaired in all cases with a multilayer closure that consisted of a sellar inlay graft (e.g., abdominal fat or collagen sponge) and a rigid sellar buttress (MEDPOR, Stryker Corp., Kalamazoo, Michigan, United States) (-Table 2). A vascularized nasal septal flap and a rigid buttress were used in $2(5 \%)$ patients who had high-flow CSF leaks.

\section{Postoperative Positive-Pressure Ventilation Use}

After surgery, 38 (90\%) patients resumed PPV use and 4 (10\%) patients chose not to resume PPV use due to improvements in their symptoms. Resumption of PPV occurred at a median of 3.5 weeks (range: $0.14-52$ weeks) after surgery. PPV device use was resumed by 16 (38\%) patients at less than 2 weeks after surgery, by 8 (19\%) patients at 2 to 7 weeks after surgery, and by $14(33 \%)$ patients at 8 weeks or more after surgery. For patients with grades 0 and 1 CSF leaks, the median time to resume PPV was 2 weeks (range: $0.14-52$ weeks). For patients with grades 2 and 3 CSF leaks, the median time to restart PPV was 9 weeks (range: $0.57-12$ weeks).

We examined potential complications for both restarting PPV and withholding PPV during the perioperative period. There were no cases of pneumocephalus or CSF leakage in the 38 patients who resumed PPV device use. However, 4 (10\%) of the 42 patients required temporary nocturnal

Table 2 Outcomes of 42 patients with obstructive sleep apnea after transsphenoidal surgery

\begin{tabular}{|l|l|}
\hline Outcome & $N(\%)^{\text {a }}$ \\
\hline $\begin{array}{l}\text { Postoperative resumption of PPV, } \\
\text { median (range) (weeks) }\end{array}$ & 3.5 (range, 0.14-52.0) \\
\hline Less than 2 wk & $16(38)$ \\
\hline $2-7$ wk & $8(19)$ \\
\hline 8 wk or longer & $14(33)$ \\
\hline Did not resume use & $4(10)$ \\
\hline $\begin{array}{l}\text { Postoperative resumption of PPV } \\
\text { median (range) (weeks) }\end{array}$ & 2 (range: $0.14-52)$ \\
\hline Grades 0, 1 & 9 (range: $0.57-12)$ \\
\hline Grades 2, 3 & \\
\hline $\begin{array}{l}\text { Complications related to } \\
\text { restarting PPV }\end{array}$ & $0(0)$ \\
\hline CSF leak, pneumocephalus & $4(10)$ \\
\hline $\begin{array}{l}\text { Complications from } \\
\text { withholding PPV }\end{array}$ & \\
\hline Home oxygen requirement & \\
\hline
\end{tabular}

Abbreviations: CSF, cerebrospinal fluid; PPV, positive-pressure ventilation.

${ }^{a}$ Values are presented as number (percentage) unless indicated otherwise. 
supplemental home oxygen for their sleep apnea. Other patients in the OSA group who had not yet resumed PPV and who had cardiopulmonary complications included one patient who required reintubation after a myocardial infarction and one patient who had a prolonged intensive care unit stay after exacerbation of chronic obstructive pulmonary disease. The relationship between delaying PPV and these two complications is indeterminate.

\section{Discussion}

Because transsphenoidal surgery creates a skull base defect, the question of when to restart patients on PPV after transsphenoidal surgery poses a management dilemma. Other authors have hypothesized that, because PPV applies nasal airway pressure to keep the airway open, patients using these devices are at a risk of intracranial complications (e.g., CSF leak, meningitis, and tension pneumocephalus) after transsphenoidal surgery. ${ }^{6,19-22}$ However, untreated OSA can also lead to complications such as pulmonary complications, impaired cardiovascular function, decreased quality of life, and fatigue. $^{27-30}$ In other surgical disciplines, patients with OSA have been found to have higher rates of postoperative complications. The other potential complication of OSA that is yet to be considered in this setting is that untreated OSA can lead to elevated intracranial pressure due to retained carbon dioxide, which may predispose patients to a CSF leak. ${ }^{24,31-33}$ It is therefore paramount to strike a balance between the risks and benefits of PPV. Currently, no guidelines exist on how to manage PPV after transsphenoidal surgery. Thus, to better understand the potential complications of resuming PPV after surgery and, conversely, the risks of delaying PPV after surgery, we reviewed our institutional experience. On the basis of these data and discussions with experts in the field, we propose a preliminary management algorithm that attempts to balance the risks and benefits of PPV devices and standardizes our approach to facilitate future studies.

\section{Key Results}

The first key result of the study is that, when PPV was resumed at a median of 3.5 weeks after surgery, no patient experienced pneumocephalus or CSF leakage. For patients with grade 0 or 1 leak, PPV was resumed at a median of 2 weeks, and for patients with higher-grade skull base defects, it was resumed at 9 weeks. Our experience is similar to that of White-Dzuro et $\mathrm{al}^{34}{ }^{34}$ who noted no complications from PPV use in a series of 25 patients. Unfortunately, the major limitation of their study was that the timing of restarting PPV was not documented. The authors stated that PPV devices were presumed to have been restarted in 2 to 4 weeks. The other important limitation is that the size of the dural defect was not documented. Furthermore, they did not report the impact of withholding PPV devices in the perioperative period. Rahimi et al $^{35}$ reported a series of 38 patients with OSA, 3 of whom reinitiated CPAP after surgery. None of these three patients had complications from CPAP. Altogether, these studies suggest that the risk of resuming PPV for OSA may not be as high as initially feared on the basis of case reports of postoperative pneumocephalus. ${ }^{36}$ These results also suggest an opportunity to tailor the use of the PPV device to particular patient characteristics such as the size of the skull base defect. We have summarized the available series in - Table 3 . $^{34,35}$

The second key result of our study addresses the potential harm to patients from withholding PPV devices in the perioperative period. Following surgery, both the nasal and oral airways may be swollen, potentially aggravating OSA. We discovered that, while most patients could be successfully managed with humidified oxygen supplied by a face tent from which they were weaned before discharge, four patients required home oxygen supplementation due to persistent nighttime hypoxemia. Furthermore, one patient was reintubated after surgery after experiencing a myocardial infarction, and one patient required a prolonged hospital stay after experiencing an exacerbation of chronic obstructive pulmonary disease. However, it is unclear whether resuming PPV would have prevented either of these singular complications, as both patients had preexisting cardiopulmonary disease.

\section{Data Interpretation and Proposed Management Algorithm}

Because this study represents a first step toward addressing the important clinical question of when to restart PPV use in patients with OSA after transsphenoidal surgery, we propose a preliminary PPV management algorithm that incorporates the size of the dural defect into clinical decision-making

Table 3 Summary of studies analyzing PPV use after transsphenoidal surgery

\begin{tabular}{|c|c|c|c|c|}
\hline Study & $\begin{array}{l}\text { No. of patients using } \\
\text { PPV before surgery }\end{array}$ & $\begin{array}{l}\text { Complications of } \\
\text { PPV resumption }\end{array}$ & $\begin{array}{l}\text { When PPV } \\
\text { was resumed }\end{array}$ & Conclusion \\
\hline Current study & $\begin{array}{l}42 \text { total, } 38 \text { resumed } \\
\text { PPV }\end{array}$ & None & $\begin{array}{l}\text { Median } 3.5 \text { wk } \\
\text { (range: } 0.14-52 \text { wk) }\end{array}$ & $\begin{array}{l}\text { Resumption of PPV appears } \\
\text { safe; not resuming PPV may } \\
\text { require more patients to be } \\
\text { discharged on oxygen }\end{array}$ \\
\hline $\begin{array}{l}\text { White-Dzuro et al, } \\
2016^{34}\end{array}$ & 25 & None & $\begin{array}{l}\text { Not documented, but } \\
\text { between } 2 \text { and } 4 \mathrm{wk}\end{array}$ & Resumption of PPV appears safe \\
\hline Rahimi et al, $2014^{35}$ & 3 & None & Postoperative day 3 & $\begin{array}{l}\text { Further studies are needed } \\
\text { to determine the safe use of } \\
\text { CPAP in patients after } \\
\text { transsphenoidal surgery }\end{array}$ \\
\hline
\end{tabular}

Abbreviations: CPAP, continuous positive airway pressure; PPV, positive-pressure ventilation. 


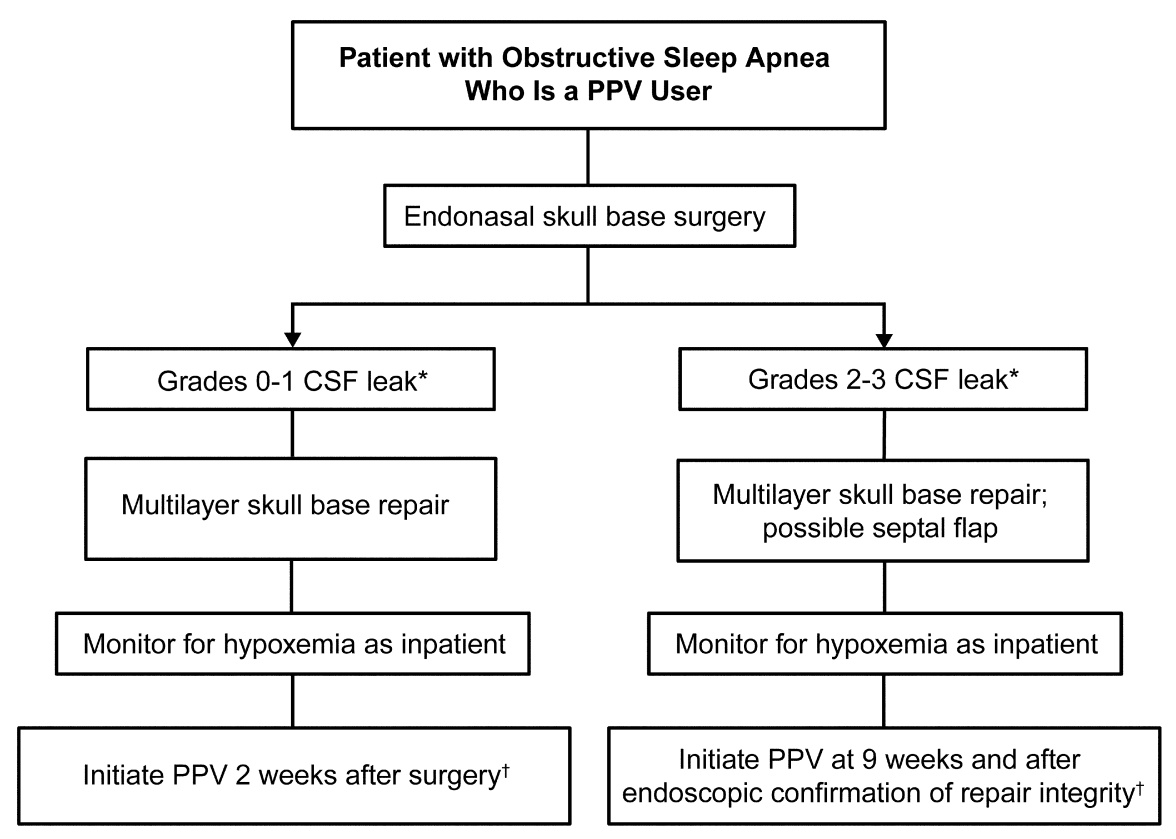

Fig. 1 Proposed management algorithm for the resumption of use of PPV devices in patients with obstructive sleep apnea after transsphenoidal surgery. Surgeons are encouraged to obtain the results of the patient's sleep study to help guide management. The algorithm encourages surgeons to tailor the use of postoperative PPV devices to the size of the dural defect and to the severity of the patient's sleep apnea. ${ }^{*}$ CSF leak grade as defined by Esposito et al. ${ }^{1}$ CSF, cerebrospinal fluid; PPV, positive-pressure ventilation. (Reproduced with permission of Barrow Neurological Institute, Phoenix, Arizona, United States.)

(-Fig. 1). ${ }^{1}$ We acknowledge the preliminary nature of this algorithm; its primary purpose is to organize how these patients are approached so that better quality data can be gathered in the future with a more homogeneous sample of patients. In this algorithm, the grade of CSF leak was used as a surrogate for the size of the dural defect and the size of the intracranial to extracranial fistula.

As a general guideline, surgeons are encouraged to obtain a sleep apnea history, including PPV device settings, from patients and to obtain the results of each patient's sleep study to understand the severity of that patient's OSA. The proposed treatment pathway favors early resumption of PPV in patients with the lowest risk of CSF leakage to help prevent the cardiac and pulmonary complications, quality of life concerns, and postoperative fatigue caused by OSA. We developed this algorithm in consultation with neurocritical care pulmonologists at our center and in discussions with leaders of other pituitary centers. Because the resumption of PPV to date has been inconsistent, performing a meaningful analysis of the practice has been limited. Following a management algorithm such as the one that we propose will allow us to study PPV more rigorously.

In patients with either no CSF leakage (grade 0 ) or a weeping CSF leak without an obvious diaphragmatic defect (grade 1) that was repaired adequately with a multilayer repair, we propose restarting PPV devices in postoperative week 2, which is the median time observed in our series for this subset of patients. This group represents the patients who are least likely to encounter a complication from restarting a PPV device and who are the best candidates for resuming PPV early. The proposed timing of resuming PPV in this lower-risk group is also supported by the data reported by White-Dzuro et al. ${ }^{34}$
In contrast, for patients with large bony and dural defects with high-flow CSF leaks (grades 2 and 3) who represent the highest risk of PPV complications, we propose restarting PPV after clear endoscopic confirmation of repair viability in the office, which occurs after a period of healing approximately 2 weeks after surgery at most centers. Our limited data set suggests that 9 weeks is a reasonable time point. Usually, flap viability is not confidently confirmed until 1 to 2 months after surgery, when the otolaryngologist is able to suction the packing and debris off the flap for inspection of the edges. We have observed that vascularized flaps exhibit attachment to the skull base as early as 4 days after surgery. Animal models of fascial dural repair demonstrate fibrous ingrowth at 2 weeks after surgery. ${ }^{20}$ Although it may be safe to resume PPV sooner than 9 weeks on the basis of these observations, our experience does not yet support doing so.

Finally, a central tenet of this proposed management pathway is that resuming PPV should not depend exclusively on the size of the skull base defect but should also take into consideration the severity of OSA in the patient. Observation of the patient's breathing mechanics and oxygenation after surgery provides useful supplemental information. Patients with severe sleep apnea who are at a risk of reintubation without PPV would be candidates to restart PPV early, whereas patients with less severe sleep apnea may be candidates to delay restarting PPV to allow more time for the skull base to heal.

Other authors have commented that the proposed algorithm may, in fact, be too conservative. Although this point may be true, the data from this series cannot yet support the practice of starting PPV devices earlier. At the very least, this 
proposed algorithm represents a first step toward trying to organize how we approach these patients. As our specialty gains more experience with this entity, more data may be accumulated to support advocating for the benefits of even earlier resumption of PPV devices.

\section{Generalizability}

This series represents an unselected cross-section of typical transsphenoidal surgery patients with comorbid OSA. Thus, we propose that the results are generalizable to other pituitary referral centers.

\section{Study Limitations}

Because there are no guidelines for resuming PPV after surgery, the primary limitation of this study is that the resumption of PPV was at the discretion of the treating neurosurgeon and consulting neurointensivist team on a case-by-case basis. The team made a judgment about when it was safe to resume PPV that took into consideration the severity of the individual patient's OSA. In most cases, otolaryngology was not involved in patient care and the decision to restart PPV. Thus, there was a wide variation in terms of when PPV was restarted, which limits the interpretation of these results. Another limitation of our study is that we were not able to determine the severity of OSA in the patient population because we were not able to obtain sleep study results in most patients, partly due to the retrospective nature of this study. Finally, our series contained relatively few patients with grades 2 and 3 CSF leaks who required PPV devices, which limits the power to detect a complication in this group of patients.

\section{Conclusion}

In this cohort of patients with OSA, the use of PPV that was resumed at a median of 3.5 weeks after transsphenoidal surgery was not associated with postoperative CSF leakage or pneumocephalus. Patients with the lowest risk of a CSF leak resumed PPV at 2 weeks postoperatively, whereas patients at higher risk resumed PPV at 9 weeks postoperatively. Although several centers have reported that PPV may play a role in certain cases of postoperative intracranial complications, this association was not observed in this larger series. Withholding PPV use after surgery resulted in some patients requiring home oxygen supplementation upon discharge. We propose an OSA management algorithm that is tailored to the size of the dural defect and the severity of OSA to standardize treatment and allow for a more rigorous study of PPV after transsphenoidal surgery. Surgeons are encouraged to obtain the OSA history of their patients before surgery.

\section{Disclosures}

Dr. Little is a stockholder in Kogent Surgical. None of the authors have anything to disclose.

\section{Funding}

This study received funding from the Barrow Neurological Foundation.
Conflict of Interest

Dr. Little reports other from Kogent Surgical, outside the submitted work.

\section{Acknowledgments}

The authors thank the staff of Neuroscience Publications at the Barrow Neurological Institute for assistance with manuscript preparation.

\section{References}

1 Esposito F, Dusick JR, Fatemi N, Kelly DF. Graded repair of cranial base defects and cerebrospinal fluid leaks in transsphenoidal surgery. Neurosurgery 2007;60(04, Suppl 2):295-303, discussion 303-304

2 Kassam AB, Prevedello DM, Carrau RL, et al. Endoscopic endonasal skull base surgery: analysis of complications in the authors' initial 800 patients. J Neurosurg 2011;114(06):1544-1568

3 Zaidi HA, Awad AW, Bohl MA, et al. Comparison of outcomes between a less experienced surgeon using a fully endoscopic technique and a very experienced surgeon using a microscopic transsphenoidal technique for pituitary adenoma. J Neurosurg 2016;124(03):596-604

4 Altinörs N, Arda N, Kars Z, et al. Tension pneumocephalus after transsphenoidal surgery: case report. Neurosurgery 1988;23 (04):516-518

5 Haran RP, Chandy MJ. Symptomatic pneumocephalus after transsphenoidal surgery. Surg Neurol 1997;48(06):575-578

6 Sawka AM, Aniszewski JP, Young WF Jr, Nippoldt TB, Yanez P, Ebersold MJ. Tension pneumocranium, a rare complication of transsphenoidal pituitary surgery: Mayo Clinic experience 19761998. J Clin Endocrinol Metab 1999;84(12):4731-4734

7 Yüceer N, Cakíroğlu K, Erdoğan A, Gökalp HZ, Bağdatoğlu C. Tension pneumocephalus after transsphenoidal surgery: two case reports. Acta Neurochir (Wien) 1995;137(1-2):58-61

8 Punjabi NM. The epidemiology of adult obstructive sleep apnea. Proc Am Thorac Soc 2008;5(02):136-143

9 Barbosa FR, Silva CM, Lima GA, et al. Prevalence of obstructive sleep apnea in patients with prolactinoma before and after treatment with dopamine agonists. Pituitary 2014;17(05):441-449

10 Smith M, Hirsch NP. Pituitary disease and anaesthesia. Br J Anaesth 2000;85(01):3-14

11 Banu MA, Szentirmai O, Mascarenhas L, Salek AA, Anand VK, Schwartz TH. Pneumocephalus patterns following endonasal endoscopic skull base surgery as predictors of postoperative CSF leaks. J Neurosurg 2014;121(04):961-975

12 Bottini P, Tantucci C. Sleep apnea syndrome in endocrine diseases. Respiration 2003;70(03):320-327

13 Colao A, Ferone D, Marzullo P, Lombardi G. Systemic complications of acromegaly: epidemiology, pathogenesis, and management. Endocr Rev 2004;25(01):102-152

14 Sze L, Schmid C, Bloch KE, Bernays R, Brändle M. Effect of transsphenoidal surgery on sleep apnoea in acromegaly. Eur J Endocrinol 2007;156(03):321-329

15 Epstein LJ, Kristo D, Strollo PJ Jr, et al; Adult Obstructive Sleep Apnea Task Force of the American Academy of Sleep Medicine. Clinical guideline for the evaluation, management and long-term care of obstructive sleep apnea in adults. J Clin Sleep Med 2009;5 (03):263-276

16 Morgenthaler TI, Kapen S, Lee-Chiong T, et al; Standards of Practice Committee; American Academy of Sleep Medicine. Practice parameters for the medical therapy of obstructive sleep apnea. Sleep 2006;29(08):1031-1035

17 Qaseem A, Holty JE, Owens DK, Dallas P, Starkey M, Shekelle P; Clinical Guidelines Committee of the American College of Physicians. Management of obstructive sleep apnea in adults: a clinical 
practice guideline from the American College of Physicians. Ann Intern Med 2013;159(07):471-483

18 Venkatraghavan L, Perks A. Postoperative management of obstructive sleep apnea after transsphenoidal pituitary surgery. J Neurosurg Anesthesiol 2009;21(02):179-180

19 Jarjour NN, Wilson P. Pneumocephalus associated with nasal continuous positive airway pressure in a patient with sleep apnea syndrome. Chest 1989;96(06):1425-1426

20 Kopelovich JC, de la Garza GO, Greenlee JD, Graham SM, Udeh CI, O'Brien EK. Pneumocephalus with BiPAP use after transsphenoidal surgery. J Clin Anesth 2012;24(05):415-418

21 Kuzniar TJ, Gruber B, Mutlu GM. Cerebrospinal fluid leak and meningitis associated with nasal continuous positive airway pressure therapy. Chest 2005;128(03):1882-1884

22 Yared J, El Annan J. Cerebrospinal fluid leak associated with nasal continuous positive airway pressure treatment for obstructive sleep apnoea. BMJ Case Rep 2010;2010:201

23 Zlotnik D, Taylor G, Simmoneau A, Viot-Blanc V, Devys JM. Two cases of pneumocephalus following noninvasive continuous positive airway ventilation after transsphenoidal neurosurgery [in French]. Ann Fr Anesth Reanim 2014;33(04):275-278

24 Abdelsattar ZM, Hendren S, Wong SL, Campbell DA Jr, Ramachandran SK. The impact of untreated obstructive sleep apnea on cardiopulmonary complications in general and vascular surgery: a cohort study. Sleep (Basel) 2015;38(08):1205-1210

25 Nagappa M, Mokhlesi B, Wong J, Wong DT, Kaw R, Chung F. The effects of continuous positive airway pressure on postoperative outcomes in obstructive sleep apnea patients undergoing surgery: a systematic review and meta-analysis. Anesth Analg 2015;120(05):1013-1023

26 Little AS, Kelly DF, Milligan J, et al. Comparison of sinonasal quality of life and health status in patients undergoing microscopic and endoscopic transsphenoidal surgery for pituitary lesions: a prospective cohort study. J Neurosurg 2015;123(03):799-807

27 Gross JB, Bachenberg KL, Benumof JL, et al; American Society of Anesthesiologists Task Force on Perioperative Management. Prac- tice guidelines for the perioperative management of patients with obstructive sleep apnea: a report by the American Society of Anesthesiologists Task Force on Perioperative Management of patients with obstructive sleep apnea. Anesthesiology 2006;104 (05):1081-1093, quiz 1117-1118

28 Jordan AS, McSharry DG, Malhotra A. Adult obstructive sleep apnoea. Lancet 2014;383(9918):736-747

29 Jonas DE, Amick HR, Feltner C, et al. Screening for obstructive sleep apnea in adults: evidence report and systematic review for the US Preventive Services Task Force. JAMA 2017;317(04): 415-433

30 Javaheri S, Barbe F, Campos-Rodriguez F, et al. Sleep apnea: types, mechanisms, and clinical cardiovascular consequences. J Am Coll Cardiol 2017;69(07):841-858

31 Xie YJ, Shargorodsky J, Lane AP, et al. Perioperative continuous cerebrospinal fluid pressure monitoring in patients with spontaneous cerebrospinal fluid leaks. Int Forum Allergy Rhinol 2015;5 (01):71-77

32 Jennum P, Børgesen SE. Intracranial pressure and obstructive sleep apnea. Chest 1989;95(02):279-283

33 Hai F, Porhomayon J, Vermont L, Frydrych L, Jaoude P, El-Solh AA. Postoperative complications in patients with obstructive sleep apnea: a meta-analysis. J Clin Anesth 2014;26(08):591-600

34 White-Dzuro GA, Maynard K, Zuckerman SL, et al. Risk of postoperative pneumocephalus in patients with obstructive sleep apnea undergoing transsphenoidal surgery. J Clin Neurosci 2016;29:25-28

35 Rahimi E, Mariappan R, Tharmaradinam S, Manninen P, Venkatraghavan L. Perioperative management and complications in patients with obstructive sleep apnea undergoing transsphenoidal surgery: our institutional experience. J Anaesthesiol Clin Pharmacol 2014;30(03):351-354

36 Wanamaker JR, Mehle ME, Wood BG, Lavertu P. Tension pneumocephalus following craniofacial resection. Head Neck 1995;17 (02):152-156 